\title{
EL PROCEDIMIENTO DE TUTELA DE DERECHOS FUNDAMENTALES DEL TRABAJADOR EN CHILE
}

\author{
Claudio Palavecino Cáceres
}

Universidad de Chile

\begin{abstract}
RESUMEN: El procedimiento de tutela laboral es una modalidad procesal que tiene por objeto conocer de lesiones a ciertos derechos fundamentales de los trabajadores y, en caso que la lesión se confirme, obtener el cese de la conducta antijurídica y medidas reparatorias. En este trabajo describo sus aspectos esenciales y formulo críticas desde un punto de vista garantista.
\end{abstract}

Palabras clave: tutela, proceso, derechos fundamentales

ABSTRACT: The labour guardianship or protection proceeding is a kind of procedure foreseen in Chilean legislation which aims to enforce key fundamental legal rights of employees by both applying legal remedies and correcting unlawful behaviour committed by employers. The aim of this paper is to examine the main features of this legal procedure and criticise it from a guarantee-based perspective.

Key words: guardianship, process, fundamental rights

\section{INTRODUCCIÓN}

El procedimiento de tutela laboral es una modalidad procesal que tiene por objeto conocer de lesiones a ciertos derechos fundamentales de los trabajadores y, en caso que la lesión se confirme, obtener el cese de la conducta antijurídica y medidas reparatorias. En su estructura no difiere mayormente del procedimiento de aplicación general para las contiendas laborales ${ }^{1}$, salvo por la ampliación de la legitimación activa a sujetos distintos del titular del derecho fundamental comprometido; la exigencia de antecedentes fundantes de la denuncia como requisito de admisibilidad de la misma y la posibilidad de anticipar la tutela en caso de lesiones de especial gravedad o cuando la vulneración denunciada pueda causar efectos irreversibles. El plazo para dictar sentencia se ha acortado de 15 a 10 días respecto del procedimiento de aplicación general.

\footnotetext{
Abogado. Profesor del Departamento de Derecho del Trabajo y la Seguridad Social de la Facultad de Derecho de la Universidad de Chile.

1 El procedimiento de aplicación general conserva la escrituración para la etapa de discusión, debiendo presentarse tanto la demanda como la contestación por escrito. El resto de las actuaciones procesales se concentran en dos audiencias orales y públicas. La primera, que se llama audiencia preparatoria, se lleva a cabo dentro de los 35 días siguientes a la resolución que acoge a trámite la demanda. Dentro de ella, eventualmente, puede concluir la fase de discusión si en la contestación el demandado hubiere opuesto excepciones o deducido reconvención, de las cuales dará traslado el juez al actor para que las conteste verbalmente.

Luego el magistrado debe hacer una relación somera de los escritos de las partes e intentar la conciliación entre ellas. Si la conciliación no se produce, el juez debe fijar los hechos sustanciales, pertinentes y controvertidos y, conforme a los términos de esa resolución, las partes ofrecerán sus pruebas y demás elementos de convicción. El juez debe resolver fundadamente sobre la pertinencia de los mismos y, eventualmente, también sobre su licitud. En esta audiencia el juez puede, además, decretar prueba de oficio. La audiencia de juicio se lleva a cabo dentro de los 30 días siguientes a la audiencia preparatoria. En la audiencia de juicio se rinde la prueba previamente admitida y las partes formulan sus observaciones y conclusiones sobre la misma. El juez puede dictar sentencia al final de la audiencia, pero lo corriente ha sido que se sirva del plazo de 15 días que dispone la ley.
} 
El objetivo de esta ponencia es describir los aspectos esenciales del procedimiento de tutela y formular algunas críticas desde un punto de vista garantista que merece, especialmente en cuanto la posibilidad de anticipar la tutela satisfactiva que el procedimiento brinda al juez.

\section{PRESUPUESTOS DE LA ACCIÓN DE TUTELA}

De acuerdo al artículo 485 inciso $1^{\circ}$ del Código del Trabajo, el procedimiento de tutela laboral contenido en el Párrafo $6^{\circ}$ del Capítulo II, Título I, del Libro V de dicho cuerpo legal, "se aplicará respecto de las cuestiones suscitadas en la relación laboral, por aplicación de las normas laborales, que afecten los derechos fundamentales de los trabajadores, entendiéndose por estos los consagrados en la Constitución Política [...], cuando aquellos derechos resulten lesionados en el ejercicio de las facultades del empleador".

También se aplicará este procedimiento para conocer de los actos discriminatorios a que se refiere el artículo. $2^{\circ}$ del Código del Trabajo ${ }^{2}$, con excepción de aquellos precontractuales a que se refiere el inciso sexto de dicho precepto (ofertas de empleo discriminatorias). También a las denuncias por discriminación en materia de remuneraciones, conforme al artículo 62 bis, inciso $2^{\circ}$ del citado cuerpo legal ${ }^{3}$.

Asimismo se aplicará este procedimiento para conocer de las represalias ejercidas en contra de trabajadores, en razón o como consecuencia de la labor fiscalizadora de la Dirección del Trabajo o por el ejercicio de acciones judiciales.

Finalmente, se aplicará este procedimiento para el conocimiento y resolución de las infracciones por prácticas desleales o antisindicales (artículo 292 incisos $3^{\circ}$ del Código del Trabajo).

\subsection{Cuestiones suscitadas "EN la Relación laboral”}

Este presupuesto limita la aplicación del procedimiento de tutela a aquellos conflictos sobre derechos fundamentales que surjan en la "relación laboral" existente entre las partes. Tal ámbito incluye desde luego a la relación laboral surgida del contrato de trabajo y que vincula al trabajador con su empleador, pero además a la relación laboral surgida del "contrato de puesta a disposición" que tiene por objeto ceder temporalmente un "trabajador de servicios transitorios" ${ }^{4}$ a una empresa "usuaria"s. Si bien la empresa cedente (Empresa de servicios transitorios ${ }^{6}$ ) conserva la condición formal de empleadora del trabajador transitorio, la empresa usuaria tendrá la facultad de organizar y

\footnotetext{
El artículo $2^{\circ}$, inciso $3^{\circ}$ define discriminación enunciando explícitamente las categorías de diferenciación ilegítimas: "Los actos de discriminación son las distinciones, exclusiones o preferencias basadas en motivos de raza, color, sexo, edad, estado civil, sindicación, religión, opinión política, nacionalidad, ascendencia nacional u origen social, que tengan por objeto anular o alterar la igualdad de oportunidades o de trato en el empleo y la ocupación".

El artículo 62 bis, establece en su inciso $1^{\circ}$ que "El empleador deberá dar cumplimiento al principio de igualdad de remuneraciones entre hombres y mujeres que presten un mismo trabajo, no siendo consideradas arbitrarias las diferencias objetivas en las remuneraciones que se funden, entre otras razones, en las capacidades, calificaciones, idoneidad, responsabilidad o productividad".

El artículo 183-F del Código del Trabajo define al trabajador de servicios transitorios como "todo aquel que ha convenido un contrato de trabajo con una empresa de servicios transitorios para se puesto a disposición de una o más usuarias de aquella...".

5 El artículo 183-F del Código del Trabajo define a la usuaria como "toda persona natural o jurídica que contrata con una empresa de servicios transitorios, la puesta a disposición de trabajadores para realizar labores o tareas transitorias u ocasionales...".

6 El artículo 183-F del Código del Trabajo define a la Empresa de Servicios Transitorios como "toda persona jurídica, inscrita en el registro respectivo, que tenga por objeto social exclusivo poner a disposición de terceros denominados para estos efectos empresas usuarias , trabajadores para cumplir en estas últimas, tareas de carácter transitorio u ocasional, como asimismo la selección, capacitación y formación de trabajadores, así como otras actividades afines en ámbito de los recursos humanos".
} 
dirigir el trabajo dentro del ámbito de las funciones para las cuales el trabajador fue puesto a su disposición (artículo 183-X del Código del Trabajo). El artículo 183-Y, inciso 2º califica el vínculo entre la usuaria y el trabajador cedido como una "relación laboral", lo que permite afirmar la legitimación procesal de las partes a efectos del procedimiento de tutela. De esto no hay duda, de una parte porque el artículo 183-Y del Código del Trabajo impone como límite a las facultades que la ley le reconoce a la usuaria "el respeto a las garantías constitucionales de los trabajadores" y, de otra, porque el artículo 183-H, del mismo cuerpo legal, señala que las cuestiones suscitadas entre los trabajadores y la o las usuarias de sus servicios "serán de competencia de los juzgados de Letras del Trabajo".

En cuanto a la relación entre el trabajador del contratista y la empresa principal generada con motivo del trabajo en régimen de subcontratación, si bien la ley admite un litisconsorcio pasivo entre el contratista empleador y la empresa principal no empleadora, éste tiene únicamente como fin que el trabajador persiga la responsabilidad por remuneraciones e indemnizaciones legales adeudadas por el contratista en el patrimonio de la empresa principal, a quien la ley impone el carácter de codeudor del contratista. En caso que el contratista viole algún derecho fundamental de su trabajador la responsabilidad a que dé lugar tal vulneración no irradia en mi opinión a la empresa principal. No al menos en virtud de lo dispuesto en el artículo 183-B del Código del Trabajo aunque ciertamente la vulneración de derechos fundamentales con ocasión del despido genere derecho a una "indemnización legal" especial porque, tal como se aclaró en la discusión legislativa del precepto, se quiso excluir del objeto de la responsabilidad de la empresa principal tanto las obligaciones de hacer como las de dar derivadas del cumplimiento por equivalencia de las obligaciones de hacer ${ }^{7}$. La exigencia de una relación laboral entre las partes impide asimismo que la empresa principal sea legitimada pasiva de la acción de tutela laboral aunque haya cometido una vulneración directa de algún derecho fundamental del trabajador del contratista, puesto que para que haya subcontratación el trabajador debe estar subordinado exclusivamente al contratista y no a la empresa principal, vale decir, si hay subcontratación no hay relación laboral entre el trabajador y la empresa principal.

En síntesis, al exigir la ley la existencia de una relación laboral entre las partes a efectos de la legitimación procesal, quedarían excluidas de esta vía de tutela las siguientes controversias sobre derechos fundamentales:

1) Aquellas en que no existe una relación laboral entre las partes en conflicto;

2) Aquellas en que se discute la existencia del vínculo (mientras no se resuelva positivamente esta cuestión previa a través del procedimiento de aplicación general); y

3) Aquellas en que existe relación laboral entre las partes en conflicto pero en que la vulneración se produce fuera del ámbito de organización y dirección del empresario. Así, a modo de ejemplo, una agresión física de un empleador a un trabajador suyo producida en un encuentro casual con ocasión de un evento social no permitiría al trabajador demandar de tutela a su empleador, salvo que como consecuencias de ese evento el empleador adoptara represalias en el lugar de trabajo.

Palavecino Cáceres, Claudio. Subcontratación. Régimen jurídico del trabajo subcontratado y del suministro de personal. Santiago, Chile: Editorial Jurídica de Chile, 2006, pp. 69. 


\subsection{QUe LA CUESTIÓN SE HAYA SUSCITADO POR APLICACIÓN DE NORMAS LABORALES}

De acuerdo con este presupuesto procesal, el procedimiento de tutela será la vía idónea solo en cuanto el conflicto surja de "la aplicación de normas laborales" y que, como consecuencia de esa aplicación se genere una afección ilegítima a los derechos fundamentales del trabajador. Al subordinar la tutela judicial primeramente a una trasgresión de normas laborales -entendidas como normas de fuente legal- y sólo secundariamente, por vía refleja, al derecho constitucional, se echa por tierra, en mi opinión, ese enfoque conflictualista, conforme al cual, al juez del trabajo correspondería resolver supuestas colisiones de derechos fundamentales a través del método de la ponderación ${ }^{8}$. Se ha dicho en tal sentido que:

"si el [...] juez debe resolver si el empleador tiene derecho a controlar el contenido de los correos electrónicos deberá determinar qué alcance tendrá el derecho de propiedad [...] frente a un derecho de equivalente valor como el de la intimidad [...] cuestión que supone un sopesamiento que podría terminar, en algunos casos, en una solución a favor de la primero como, en otros, a favor de la segunda?

Con ocasión de la primera tutela laboral acogida en Chile autorizada doctrina manifestó serios reparos a este enfoque que, irreflexivamente, ha venido "confundiendo conceptos básicos de la teoría constitucional, desnaturalizando algunos conceptos elementales de derecho constitucional y otorgando una aplicación desmesurada y peligrosa a la doctrina germana de la drittwirkung" ${ }^{10}$. Con posterioridad se han alzado voces críticas en la doctrina chilena que reivindican el protagonismo de la ley a la hora de resolver sobre la lesión derechos fundamentales en las relaciones laborales ${ }^{11}$. Lo cierto es que la norma procesal mantiene el rol fundamental del juez como aplicador de la ley, puesto que una vez acreditada la afectación de la esfera protegida por el derecho fundamental el juicio se resuelve en la determinación de la juridicidad/antijuridicidad de la conducta del empleador, vale decir, en un examen sobre la legalidad de su actuar ${ }^{12}$.

\footnotetext{
8 Gamonal, Sergio. El procedimiento de tutela de derechos laborales. Santiago, Chile: LexisNexis, 2007, pp. 29-48.

9 Ugarte, José. Tutela de derechos fundamentales del trabajador. Santiago, Chile: Legalpublishing, 2009, p. 68.

10 Ferrada, Juan Carlos. "Abriendo camino en la tutela de derechos fundamentales en materia laboral: buenas intenciones, malos instrumentos (Juzgado de Letras del Trabajo de Copiapó)”, en: Revista de Derecho, vol.21, n.2, 2008, Valdivia, Chile, p. 269.

11 Silva, Luis Alejandro. "Supremacía constitucional y tutela laboral”, en: Revista de Derecho, vol.24, n.1, 2011, Valdivia, Chile, pp. 31-48. Ferrada, Juan Carlos; Walter, Rodolfo. "La protección de los derechos fundamentales de los trabajadores en el nuevo procedimiento de tutela laboral”, en: Revista de Derecho, vol.24, n.2, 2011, Valdivia, Chile, pp. 91-111.

12 Un esquema de razonamiento que podría seguir un juez del trabajo al momento de fundamentar su decisión sobre la tutela laboral es el siguiente: un primer nivel de análisis, abstracto, cuyo objetivo es determinar si la conducta del empleador, materia de la denuncia, puede afectar la esfera de protección de la libertad invocada por el trabajador; lo cual exige a su vez determinar la esfera de protección de tal libertad a partir del texto constitucional, el cual, casi siempre lacónico, invita al juez a recurrir también a los tratados internacionales y especialmente a la ley como delimitadora natural de las libertades, a la jurisprudencia del Tribunal Constitucional, y a la de las cortes que han fallado acciones de protección y de tutela laboral; y a la doctrina científica.

$\mathrm{s}_{\mathrm{i}}$ a priori no aparece que la conducta denunciada pueda afectar la esfera protegida por la libertad, ya sea porque tal conducta es inidónea o porque el trabajador sobrepasó tal esfera mediante un comportamiento ilícito, la tutela deberá ser desechada.

$s_{i}$, en cambio, la conducta denunciada tiene la virtualidad de afectar el ámbito protegido por la libertad, el juez deberá pasar al segundo nivel del análisis: en una segunda etapa el juez debe valorar la prueba rendida sobre la conducta de empleador y sus consecuencias.

${ }^{\text {A } q u i ́ ~ s e ~ t r a t a ~ d e ~ d e t e r m i n a r ~ s i ~ e f e c t i v a m e n t e ~ e l ~ e m p l e a d o r ~ i n c u r r i o ́ ~ e n ~ l a ~ c o n d u c t a ~ d e n u n c i a d a ~ y ~ c u a ́ l e s ~ f u e r o n ~ s u s ~ e f e c t o s ~ o ~ c o n s e c u e n c i a s ~}$ prácticas. Si el trabajador no logra aportar siquiera indicios que permitan presumir al juez tal conducta ni sus consecuencias o bien si empleador aporta prueba en contra a la que el juez asigne mayor valor, la tutela será rechazada. Por el contrario, si el trabajador prueba la conducta y sus consecuencias, el juez deberá pasar al último nivel de su análisis.

${ }^{\mathrm{E}}$ ste tercer y último nivel parte de haberse ya constatado una conducta del empleador que afecta una libertad fundamental del
} 


\subsection{LA VULNERACIÓN DEBE AFECTAR DERECHOS FUNDAMENTALES DEL TRABAJADOR}

En el procedimiento de tutela, los derechos fundamentales cumplen una doble función puesto que conforman y a la vez limitan el objeto del proceso. Su función de límite de la cognitio judicial a través de esta especial modalidad procesal, viene señalada inequívocamente por el artículo 487 del Código del Trabajo, el cual establece que "este procedimiento queda limitado a la tutela de derechos fundamentales a que se refiere el artículo 485". Quedan notoriamente excluidos los derechos fundamentales que se entienden formar parte de la Constitución en forma mediata a través de su artículo $5^{\circ}$ que incorpora los tratados sobre derechos humanos (bloque de constitucionalidad), e incluso varios derechos fundamentales del catálogo contenido en su artículo 19. "Si bien en un comienzo se propuso la inclusión de todos los derechos humanos, una garantía abierta"13.

Los derechos fundamentales del trabajador susceptibles de tutela a través de este procedimiento son los siguientes:

1) El derecho a la vida y a la integridad física y psíquica de la persona siempre "que su vulneración sea consecuencia directa de actos ocurridos en la relación laboral”.

2) El respeto y protección a la vida privada y a la honra de la persona y de su familia.

3) La inviolabilidad de toda forma de comunicación privada.

4) La libertad de conciencia, la manifestación de todas las creencias y el ejercicio libre de todos los cultos.

5) La libertad de emitir opinión y la de informar.

6) La libertad de trabajo y el derecho a su libre elección.

7) El derecho a no ser discriminado por motivo de raza, color, sexo, edad, estado civil, sindicación, religión, opinión política, nacionalidad, ascendencia nacional u origen social.

8) El derecho a no ser discriminado en materia de remuneraciones.

trabajador. Aquí el objetivo es determinar si esa afectación es o no antijurídica. Dado que el ordenamiento jurídico laboral concibe al empleador como titular de ciertas facultades y sujeto de imputación de ciertos deberes, se trata de determinar si, en efecto, obró en cumplimiento de alguno de tales deberes o en el ejercicio legítimo de alguna facultad legal.

${ }^{\mathrm{P}}$ or tanto, el juez debe examinar, primero, si la conducta del empleador tiene cobertura legal y, de existir esa habilitación, si actuó dentro de la misma o bien la sobrepasó. El ejercicio legítimo de la facultad legal invocada supone precisamente que el empleador ha sido capaz de probar que ha obrado con justificación suficiente y proporcionadamente. En tal caso la tutela deberá ser desechada. Si, en cambio, el empleador carecía de facultad legal para interferir la libertad del trabajador o, poseyéndola, la ejerció "sin justificación suficiente, en forma arbitraria o desproporcionada” (art. 485 inc. 3º), la tutela deberá ser acogida por el juez.

13 Aguilar, Gonzalo; Contreras, Cristian. "El efecto horizontal de los derechos humanos y su reconocimiento expreso en las relaciones laborales en Chile”, en: Ius et Praxis, vol. 13, n', Talca, Chile, 2007, pp. 205-243. 
9) La libertad sindical, pero solo mediante la persecución de las prácticas antisindicales y desleales tipificadas en el Código del Trabajo.

De acuerdo al tenor del artículo 485 del Código del Trabajo la lesión de los derechos fundamentales debe haber efectivamente acaecido para que prospere la acción de tutela, puesto que señala como presupuesto de la misma el que "aquellos resulten lesionados". Por su parte, el artículo 486 inciso final del mismo cuerpo legal exige que la denuncia se interponga dentro de los sesenta días contados "desde que se produzca la vulneración de derechos fundamentales alegada". Todavía más claro queda en el artículo 495 del citado código, que establece el contenido de la sentencia de tutela, el cual señala como primera mención "la declaración de existencia o no de la lesión de derechos fundamentales denunciada”.

El fin de la tutela laboral no es, pues, preventivo, sino reparatorio. De manera que la tutela ofrecida no es inhibitoria, sino de remoción del ilícito. Este tipo de tutela no busca evitar o prevenir la violación de los derechos, sino que es una tutela que opera después de la práctica del hecho ilícito ${ }^{14}$. De ahí que el citado artículo 495 prescriba al juez, una vez declarada la existencia de la lesión, "ordenar, de persistir el comportamiento antijurídico a la fecha de dictación del fallo, su cese inmediato."

La conducta del empleador transgrede en el plano normativo el mandato jurídico contenido en el artículo $5^{\circ}$ inciso $1^{\circ}$ del Código del Trabajo, a saber, que "el ejercicio de las facultades que la ley reconoce al empleador, tiene como límite el respeto a las garantías constitucionales". Tal mandato de respeto no entraña conferir a las libertades fundamentales del trabajador un carácter absoluto, hegemónico e infranqueable respecto de las posibilidades de actuación del empleador. De una parte porque eso inhibiría prácticamente la actividad empresarial y, de otra, porque el contrato de trabajo supone la asunción por el trabajador de la condición de subordinado, esto es, supone por definición la asunción de límites a sus libertades. Por tanto, el orden jurídico laboral legitima un cierto grado de afectación de la esfera de protección de las libertades y reacciona solo cuando el empleador se extralimita, se sobrepasa, vale decir, cuando "limita el pleno ejercicio de aquéllas sin justificación suficiente, en forma arbitraria o desproporcionada o sin respeto a su contenido esencial" (artículo 485 inciso $3^{\circ}$ del Código del Trabajo). De ahí que, incluso cuando de los antecedentes aportados por la parte denunciante resulten indicios suficientes de que se ha producido la vulneración, se permita al empleador "explicar los fundamentos de las medidas adoptadas y de su proporcionalidad" (artículo 493 del Código del Trabajo).

\section{LEGITIMACIÓN}

\subsection{Legitimados activos}

En el procedimiento de tutela laboral, el legislador radicó la legitimación activa exclusivamente en el titular del derecho afectado cuando su vulneración se produce con ocasión del despido (artículo. 489 , inc. $1^{\circ}$, del Código del Trabajo) y, en cambio, la amplió, hasta casi llegar a la acción pública, cuando la lesión a los derechos constitucionales se verifica durante la vigencia del contrato laboral. En efecto, según el artículo. 486 del Código del Trabajo la legitimación activa se expande a "cualquier trabajador u organización sindical que, invocando un derecho o interés legítimo, considere lesionados derechos fundamentales...”. Como advierte la doctrina nacional: "el

Marinoni, Luis Guilherme. Tutelas urgentes y tutelas preventivas Lima, Perú: Communitas, 2010, p. 58. 
Código no parece exigir que la lesión afecte directamente al trabajador denunciante, sino que perfectamente podría estimarse que tiene un interés legítimo cuando la vulneración la ha sufrido, por ejemplo otro trabajador de la misma empresa. Lo mismo ocurre con la organización sindical" 15 .

Por tanto, un trabajador cualquiera y la organización sindical, aun cuando no sean los directamente agraviados pueden incoar la acción de tutela, en la medida que posean un "interés legítimo" en ello. Según un autor nacional

"la idea de interés legítimo no es de utilización frecuente en el derecho chileno. Su uso se ha ido expandiendo en el derecho comparado como una forma de superar la determinación restrictiva de la legitimación activa en torno exclusivamente a la titularidad individual del derecho subjetivo, lo que se hace necesario especialmente con la recepción en el derecho moderno de intereses difusos y colectivos. Se trata de una técnica intermedia o a mitad de camino entre la restricción máxima que supone la titularidad de acciones derivadas de derechos individuales, como es el grueso en materia laboral, y la ampliación excesiva que importan acciones públicas o de interés público, como la recién incorporada en el artículo 17 del Código del Trabajo para la denuncia del trabajo infantil... "16.

Por su parte, la Inspección del Trabajo deberá denunciar y podrá hacerse parte en el proceso (conforme al artículo 486, inciso $4^{\circ}$, del Código del Trabajo). En efecto, las inspecciones del trabajo tienen el deber de denunciar, dentro de sesenta días, cuando en el ejercicio de sus facultades fiscalizadoras toma conocimiento de una vulneración de derechos fundamentales, pudiendo hacerse parte, pero la ley les exige que previamente lleve a cabo una mediación a fin de agotar las posibilidades de corrección de las infracciones constatadas.

Tenemos, pues, cuatro legitimados activos: el titular del derecho fundamental vulnerado; cualquier trabajador; la organización sindical; y la Inspección del Trabajo.

El sindicato puede actuar, además, como tercero coadyuvante. En efecto, "cuando el trabajador afectado por una lesión de derechos fundamentales haya incoado una acción conforme a las normas de este Párrafo, la organización sindical a la cual se encuentre afiliado, directamente o por intermedio de su organización de grado superior, podrá hacerse parte en el juicio como tercero coadyuvante" (artículo. 486, inciso. $2^{\circ}$, del Código del Trabajo).

Un autor nacional justifica la concesión de legitimación activa a las organizaciones sindicales señalando que:

“ello permitirá que en controversias complejas, como son aquellas en que va envuelta la vulneración de un derecho fundamental, los trabajadores afiliados cuenten con el respaldo y asesoría de su sindicato, con lo cual se está reforzando también los fines principales de estas organizaciones [...] A su vez, la intervención de los sindicatos en estos procesos contribuirá sin duda a romper la inercia constatada en muchas situaciones de vulneración de derechos fundamentales [...] particularmente, frente a controversias que por estos hechos

\footnotetext{
15 Walter, Rodolfo; Lanata, Gabriela. Régimen legal del nuevo proceso laboral chileno. Estudio de las modificaciones introducidas por las leyes $N^{\circ}$ 20.022, 20.023 y 20.087. Segunda edición. Santiago, Chile: Lexis Nexis, 2007, p. 167.

16 UGaRTE, José. "La tutela de derechos fundamentales y el derecho del trabajo: de erizo a zorro", en: Revista de Derecho, vol. 20, $\mathrm{n}^{\circ}$ 2, 2007, Valdivia, Chile.
} 
se susciten durante la vigencia de la relación laboral, atendido el temor de los trabajadores a sufrir represalias por parte del empleador y, por sobre todo, el riesgo de ser despedidos"17

De manera excepcionalísima, puede ser también legitimado activo el empleador. Esta suerte de anomalía se produce por la circunstancia de haberse sustituido el procedimiento especial de prácticas antisindicales y desleales precisamente por el procedimiento de tutela, puesto que en nuestro orden jurídico los atentados contra la libertad sindical pueden ser cometidos por los trabajadores, por las organizaciones sindicales e incluso por terceros ${ }^{18}$.

Me parece criticable la ampliación de la legitimación activa a sujetos distintos del titular del derecho fundamental agraviado. Resulta inquietante que terceros puedan incoar el procedimiento independientemente, incluso en ignorancia o contra la voluntad del trabajador titular del derecho fundamental. Tiene razón un autor nacional cuando advierte, a propósito de la acción constitucional de protección, cuya legitimación activa ha sido indiscriminadamente extendida por la jurisprudencia, que de esta manera:

"[se] tiende a vaciar de sentido la idea de titularidad" [puesto que lo que caracteriza este concepto] es la facultad de su titular para decidir el ejercicio de su propio derecho [y, en el fondo] lo que se ha hecho es privar al titular de su condición de tal, desde el momento en que ya no se encuentra en condiciones decidir sobre el ejercicio de su derecho"19.

\subsection{Legitimados pasivos}

En principio, el legitimado pasivo es el empleador ${ }^{20}$, sea persona natural o jurídica, susceptible de ser emplazado a través de quienes ejercen habitualmente funciones de dirección o administración por cuenta o representación de aquél ${ }^{21}$.

Con todo debe recordarse lo ya dicho en cuanto a que, de manera excepcional. El legislador laboral ha permitido convocar a terceros ajenos al contrato de trabajo ante la jurisdicción laboral generando hipótesis de litis-consorcio pasivo propósito del trabajo en régimen de subcontratación.

\footnotetext{
17 Canmaño, Eduardo. "La tutela jurisdiccional del derecho fundamental a la no discriminación por razones de sexo. Un análisis desde la perspectiva del proyecto de reforma al procedimiento laboral”, en: Derechos Fundamentales. Homenaje al profesor Patricio Novoa Fuenzalida. Santiago, Chile: Anuario de la Sociedad Chilena de Derecho del Trabajo y de la Seguridad Social, n³, 2004, p.226.

18 Así, por ejemplo, el art. 290 CT señala que incurre en práctica antisindical "el que de cualquier modo presione al empleador a fin de imponerle la designación de un determinado representante, de un directivo u otro nombramiento importante para el procedimiento de negociación y el que se niegue a negociar con los representantes del empleador exigiendo su reemplazo o la intervención personal de éste" y "los miembros del directorio de la organización sindical que divulguen a terceros ajenos a éste los documentos o la información que hayan recibido del empleador y que tengan el carácter de confidencial o reservados".

19 Aldunate, Eduardo. Derechos Fundamentales. Santiago, Chile: Legal Publishing, 2008, p. 160.

20 El artículo $3^{\circ}$ letra a) del Código del Trabajo define empleador como "la persona natural o jurídica que utiliza los servicios intelectuales o materiales de una o más personas en virtud de un contrato de trabajo".

21 Conforme lo dispuesto en el artículo $4^{\circ}$ inciso $1^{\circ}$ del Código del Trabajo "para los efectos previstos en este Código, se presume de derecho que representa al empleador y que en tal carácter obliga a éste con los trabajadores, el gerente, el administrador, el capitán de barco y, en general, la persona que ejerce habitualmente funciones de dirección o administración por cuenta o representación de una persona natural o jurídica”.
} 
Agreguemos que, excepcionalmente, la empresa principal podría ser legitimada pasiva en caso de incurrir en prácticas antisindicales contra las organizaciones sindicales y/o los trabajadores de la empresa contratista, toda vez que el código del trabajo tipifica y sanciona las prácticas antisindicales y desleales cometidas por terceros y, como ya se indicó, el artículo 292 inciso $3^{\circ}$ del Código del Trabajo, integra a la orbita material del procedimiento de tutela la denuncia, investigación y sanción de la totalidad de dichas practicas.

Situación más compleja se presenta frente a casos de ocultamiento de la persona del empleador, ya sea mediante subcontratación simulada o mediante la utilización simultánea de trabajadores por grupos de sociedades ya que en estos casos el trabajador aparecerá formalmente vinculado a una persona natural o jurídica pero sus servicios los prestará materialmente para otra $\mathrm{u}$ otras con las que no posee contrato formal. En mi opinión, el alzamiento del velo corporativo y la individualización correcta del empleador debe realizarse con arreglo a las figuras previstas en el artículo 507 del Código del Trabajo ${ }^{22}$ como una cuestión previa a través del procedimiento general.

\section{LA ANTICIPACIÓN DE LA TUTELA}

El artículo 492 del Código del Trabajo permite al juez, de oficio o a petición de parte, sin audiencia previa del afectado, ni admisión de recurso alguno contra la resolución, suspender los efectos del acto impugnado desde el mismo minuto que llega a su conocimiento la denuncia. En efecto, la norma citada dispone que:

"el juez, de oficio o a petición de parte, dispondrá en la primera resolución que dicte, la suspensión de los efectos del acto impugnado, cuando aparezca de los antecedentes acompañados al proceso que se trata de lesiones de especial gravedad o cuando la vulneración denunciada pueda causar efectos irreversibles, ello, bajo apercibimiento de multa de 50 a $100 \mathrm{UTM}^{23}$, la cual podrá repetirse hasta obtener el debido cumplimiento de la medida decretada. Deberá también hacerlo en cualquier tiempo, desde que cuente con dichos antecedentes. Contra estas resoluciones no procederá recurso alguno".

Se ha querido ver en esta disposición una modalidad de ejercicio de la función cautelar del juez en el proceso laboral, pero ello no es más que una confusión conceptual. La norma del artículo 492 no configura una tutela cautelar sino una tutela anticipatoria ${ }^{24}$ :

"La tutela cautelar se destina a asegurar la efectividad de la tutela satisfactiva del derecho material [...] La tutela cautelar es un instrumento de la tutela satisfactiva, en la medida que busca garantizar su fructuosidad [...] La tutela anticipatoria, sin embargo, es satisfactiva del derecho material, permitiendo su realización -y no su seguridad- mediante un cognición sumaria de verosimilitud [...] la tutela anticipatoria tiene el mismo contenido de la

\footnotetext{
22 El artículo 507 del Código del Trabajo sanciona "al empleador que simule la contratación de trabajadores a través de terceros" y al "que utilice cualquier subterfugio, ocultando, disfrazando o alterando su individualización o patrimonio y que tenga como resultado eludir el cumplimiento de las obligaciones laborales y previsionales que establece la ley o la convención”.

23 La multa va de USD 3.750 a USD 7.500 al $1^{\circ}$ de abril de 2014.

24 Palavecino, Claudio. "La reforma procesal laboral chilena. Una visión crítica desde el garantismo procesal”, en: Revista Laboral Chilena, julio 2012, Santiago, Chile, pp. 65.
} 
tutela final [...] La tutela anticipatoria es la tutela final anticipada con base en la cognición sumaria" 25 .

La "suspensión de los efectos del acto impugnado" prevista en el artículo 492 del Código del Trabajo es la anticipación del "cese inmediato" del comportamiento antijurídico que deberá ordenar el juez en la sentencia definitiva conforme el artículo $495 \mathrm{~N}^{\circ} 2$ del mismo cuerpo legal, operando el mismo apercibimiento de multa en ambos casos.

La cognición sumaria de verosimilitud la hará el juez a partir "de los antecedentes acompañados al proceso". Tales antecedentes son que fundamentan la denuncia y que por mandato del artículo 490 del Código del Trabajo, deben acompañarla como requisito de admisibilidad de la misma.

Es razonable que la medida se adopte mediante una cognición sumaria en lugar de una cognición "agotada y definitiva”. Como señala un procesalista brasileño:

"Quien desvía los ojos de la moldura técnica del proceso civil y pasa a preocuparse por la "tutela de los derechos", deja de lado la relación entre satisfactividad y cosa juzgada material, ya que la efectividad de la tutela de un derecho no presupone la cosa juzgada. Aunque la misma tenga gran importancia, la tutela del derecho se otorga independientemente de la cosa juzgada, incluso porque la tutela del derecho, para ser efectiva, en muchos casos tiene que prestarse con base en una cognición sumaria" 26 .

Pero en cambio sí resulta altamente cuestionable desde el punto de vista de la garantía del debido proceso que la parte que no ha sido previamente oída, deba soportar de inmediato y sin posibilidad de impugnación, el perjuicio sobre su interés que le provoca la resolución del tribunal.

La tutela anticipatoria en el procedimiento de tutela laboral chileno parece tomada de la figura contenida en el artículo 178 de la Ley de Procedimiento Laboral española, la cual, a diferencia de la chilena, opera sólo frente a unos supuestos restringidos y admite alegaciones y pruebas sobre la suspensión solicitada, vale decir respeta los principios de audiencia y contradicción ${ }^{27}$.

Precisamente el respeto los principios de audiencia y contradicción exige, en mi opinión que, como mínimo, el juez dé tramitación incidental a la solicitud del denunciante de suspensión de los efectos del acto impugnado o, si la decretare de oficio, lo haga con citación del denunciado. Todo ello con miras a abrir al resistente la posibilidad de discutir la necesidad de la tutela anticipatoria y los presupuestos legales de la misma y ofrecer prueba en contrario.

\footnotetext{
MarinONI, Luis Guilherme, op. cit. (n. 14), p. 33.

26 Ibid., p. 36.

$27 \quad$ El artículo 178 de la Ley de Procedimiento Laboral española dispone. “1. En el mismo escrito de interposición de la demanda el actor podrá solicitar la suspensión de los efectos del acto impugnado. Sólo se podrá deducir esta petición cuando se trate de presuntas lesiones que impidan la participación de candidatos en el proceso electoral o el ejercicio de la función representativa o sindical respecto de la negociación colectiva, restructuración de plantillas y otras cuestiones de importancia trascendental que afecten al interés general de los trabajadores y que puedan causar daños de imposible reparación.

"2. Dentro del día siguiente a la admisión de la demanda, el Juzgado o Tribunal citará a las partes ya Ministerio Fiscal para que, en el día y hora que se seńale dentro de las cuarenta y ochos horas siguientes, comparezcan a una audiencia preliminar, en la que sólo se admitirán alegaciones y pruebas sobre la suspensión solicitad.

"3. El órgano judicial resolverá en el acto mediante auto dictado de viva voz, adoptando, en su caso, las medidas oportunas para reparar la situación”.
} 
Insisto sobre la necesidad de que se adopte todas las medidas que permitan evitar que producto de dilaciones, la tutela se vuelva ineficaz. En este sentido me parece inoficiosa la primera de las causales que justifica la adopción de la medida de suspensión; a saber: "lesiones de especial gravedad", habida cuenta de la supremacía que los derechos fundamentales ostentan dentro de nuestro sistema jurídico comparativamente con cualesquiera otros bienes o intereses susceptibles de protección, de manera tal que cualquiera trasgresión al mandato de respeto sobre los mismos resulta siempre a priori gravemente antijurídica, configura siempre un súper ilícito, de no haber cobertura legal para la conducta que produce su afectación. Entrar en una etapa procesal tan temprana a realizar una calificación sobre la mayor o menor gravedad de la lesión, importa por una parte el peligro de subvaloración o banalización del mandato de respeto de los derechos fundamentales y, por otra, un prejuzgamiento cuando todavía no se cuenta con la totalidad de elementos de convicción para efectuar semejante ponderación. Además revela una incomprensión de la tutela de remoción del ilícito, puesto que para su procedencia "es suficiente la trasgresión de un mandato jurídico, no teniendo importancia si el interés privado tutelado por la norma fue efectivamente lesionado o si ocurrió un daño"28.

Si alguna justificación pudiera haber para la anticipación de la tutela de remoción del ilícito, no podría ser otra que el periculum in mora, vale decir que, los tiempos procesales implicaran que "la vulneración denunciada pueda causar efectos irreversibles”, esto es, que tornare inútil o extemporáneo el contenido de la sentencia de tutela.

Con todo, dada la gravedad que para la parte denunciada implican las tempranas medidas satisfactivas y la propia celeridad del procedimiento oral, el juez laboral deberá ser especialmente celoso en la concesión de esta tutela a la que, sin duda debe asignársele un carácter excepcionalísimo, considerando la gravedad de las sanciones que tanto patrimonialmente como personalmente pudieran afectarle. En general así ha ocurrido en la práctica.

\section{REFLEXIÓN FINAL}

Análogo entusiasmo al que en su época generó el "recurso de protección", ha despertado el procedimiento de tutela de los derechos fundamentales del trabajador, introducido por la ley 20.087. Salvo una posición firmemente $\mathrm{crítica}^{29}$, la generalidad de la doctrina juslaboralista chilena no ha escatimado alabanzas a esta modalidad procesal, señalándola como "una novedad muy bienvenida"30; "una innovación en el sentido correcto" ${ }^{11}$ verdadero hito fundacional comparable a la

\footnotetext{
$28 \quad$ Marinoni, Luis Guilherme, op. cit. (n. 14), p. 58.

29 Palavecino, Claudio. "Procedimiento de tutela laboral y debido proceso", en: La Semana Jurídica, n³36, 2007 a, p. 2; Él mismo. "Procedimiento de tutela laboral ¿El fin justifica los medios?”, en: La Semana Jurídica, 2007 b, n³33, p. 3.

30 Aguilar, Gonzalo; Contreras, Cristian, op. cit (n. 13).

31 CaAmaño, Eduardo. "El procedimiento de tutela: una innovación en el sentido correcto”, en: La Semana Jurídica, n 335 , p. 2.
} 
"ley de la silla" ${ }^{32}$ vaticinando que dará lugar a los más virtuosos efectos sobre nuestra cultura jurídica ${ }^{33}$ y concluyendo que "sin duda, favorecerá una protección más adecuada de los trabajadores"34.

Pero si grande ha sido el entusiasmo, grande podría ser también la desilusión. Nuestra propia experiencia respecto de la acción constitucional de protección y la experiencia comparada en materia de tutela judicial de los derechos fundamentales aconsejan un saludable pesimismo

En efecto, la tutela judicial directa de los derechos fundamentales, en lugar de jugar a favor de su protección, termina muchas veces atentando contra las libertades. Nacidos para proteger al individuo frente a la insaciable voluntad de poder de Leviatán, los derechos fundamentales terminan siendo la mejor excusa para que el Estado-Juez restrinja arbitrariamente las libertades de los privados.

Por otra parte la fórmula genere una inquietante disminución del protagonismo de la ley (en definitiva de los órganos deliberativos democráticos) en la tarea delimitadora de los derechos fundamentales y reguladora de los conflictos individuales y su sustitución por el juez (que adolece de un notorio déficit democrático)

En tercer término, el desborde panconstitucional pone en cuestión la autonomía privada como fuente legítima de limitaciones a los derechos fundamentales. Su configuración como derechos subjetivos queda vaciada de contenido al integrarse en las diversas nociones de orden público y resultar de ese modo notoriamente perjudicada su disponibilidad.

Finalmente la tutela judicial directa genera una pérdida del carácter general y abstracto de los límites de cada derecho fundamental y su abandono al casuismo judicial generando incerteza jurídica y caprichosos límites a las libertades.

Existen otras posibilidades de solución del conflicto a que da lugar la denuncia por vulneración de derechos fundamentales que no pasan ni por imaginar su colisión con otros derechos de igual naturaleza, ni por el método de la ponderación. El procedimiento de tutela laboral chileno admite una lectura que permite recobrar el protagonismo de la ley a la hora de resolver sobre la lesión derechos fundamentales en las relaciones laborales.

\section{BIBLIOGRAFÍA}

Aguilar, Gonzalo; Contreras, Cristian. "El efecto horizontal de los derechos humanos y su reconocimiento expreso en las relaciones laborales en Chile", en: Ius et Praxis, vol. 13, n¹, Talca, Chile, 2007, pp. 205-243.

Aldunate, Eduardo. Derechos Fundamentales. Santiago, Chile: Legal Publishing, 2008.

Caamaño, Eduardo. "El procedimiento de tutela: una innovación en el sentido correcto", en: La Semana Jurídica, n 335 , p. 2.

Caamaño, Eduardo. "La tutela jurisdiccional del derecho fundamental a la no discriminación por razones de sexo. Un análisis desde la perspectiva del proyecto de reforma al procedimiento laboral", en: Derechos Fundamentales.

\footnotetext{
32 Ugarte, José. Tutela de derechos... (n. 9).

33 Afirman que "fortalecerá la posición de los derechos humanos en el ordenamiento jurídico global chileno, promoverá sin duda el debate y la discusión en torno a los derechos humanos en Chile, extendiéndola a otras disciplinas jurídicas distintas al derecho constitucional (...), contribuirá a que la discusión por parte de los operadores jurídicos respecto de los derechos humanos no sea tan distante de los casos de la vida real, como a veces se la percibe (...), colaborará a un debate razonado y sereno por parte de todos los operadores jurídicos acerca de la eficacia de los derechos humanos, desvinculado de cualquiera identificación histórica (y) facilitará, evidentemente, el camino al juez laboral y producirá en este mismo juez un efecto reforzador de la confianza para efectuar una protección concreta de los derechos humanos de los trabajadores.” ¡Sancta simplicitas! Aguilar, Gonzalo; Contreras, Cristian, op. cit (n. 13).

34 Gamonal, Sergio, op. cit. (n. 8).
} 
Homenaje al profesor Patricio Novoa Fuenzalida. Santiago, Chile: Anuario de la Sociedad Chilena de Derecho del Trabajo y de la Seguridad Social, n³, 2004, pp.226-227.

Ferrada, Juan Carlos; Walter, Rodolfo. "La protección de los derechos fundamentales de los trabajadores en el nuevo procedimiento de tutela laboral”, en: Revista de Derecho, vol.24, n.2, 2011, Valdivia, Chile, pp. 91-111.

Ferrada, Juan Carlos. "Abriendo camino en la tutela de derechos fundamentales en materia laboral: buenas intenciones, malos instrumentos (Juzgado de Letras del Trabajo de Copiapó)”, en: Revista de Derecho, vol.21, n.2, 2008, Valdivia, Chile, pp. 251-271.

Gamonal, Sergio. El procedimiento de tutela de derechos laborales. Santiago, Chile: LexisNexis, 2007.

Marinoni, Luis Guilherme. Tutelas urgentes y tutelas preventivas Lima, Perú: Communitas, 2010.

Palavecino, Claudio. "La reforma procesal laboral chilena. Una visión crítica desde el garantismo procesal", en: Revista Laboral Chilena, julio 2012, Santiago, Chile, pp. 59-68.

Palavecino Cáceres, Claudio. Subcontratación. Régimen jurídico del trabajo subcontratado y del suministro de personal. Santiago, Chile: Editorial Jurídica de Chile, 2006, pp. 69.

Palavecino, Claudio. "Procedimiento de tutela laboral y debido proceso", en: La Semana Jurídica, n³36, 2007 a, p. 2.

Palavecino, Claudio. "Procedimiento de tutela laboral ¿El fin justifica los medios?", en: La Semana Jurídica, 2007 b, $\mathrm{n}^{\circ} 333$, p. 3;

Silva, Luis Alejandro. "Supremacía constitucional y tutela laboral", en: Revista de Derecho, vol.24, n.1, 2011, Valdivia, Chile, pp. 31-48.

Ugarte, José. Tutela de derechos fundamentales del trabajador. Santiago, Chile: Legalpublishing, 2009.

Ugarte, José. "La tutela de derechos fundamentales y el derecho del trabajo: de erizo a zorro", en: Revista de Derecho, vol. 20, n², 2007, Valdivia, Chile.

Walter, Rodolfo; Lanata, Gabriela. Régimen legal del nuevo proceso laboral chileno. Estudio de las modificaciones introducidas por las leyes $N^{\circ}$ 20.022, 20.023 y 20.087. Segunda edición. Santiago, Chile: Lexis Nexis, 2007. 